Session ????

\title{
Benefits of Undergraduate Research and Independent Study
}

\author{
Dr. Scott Kiefer, Dr. Nihad Dukhan \\ Tri-State University / University of Puerto Rico at Mayaguez
}

\begin{abstract}
It can be very difficult for junior faculty members to find the time required to develop new courses and to establish a research program while continuing to dedicate the time necessary for students in their regular teaching load. One way to maximize the benefit of time spent is to teach small independent study courses with research projects that help prepare students for graduate school and evaluate course material to be used later in new course offerings.
\end{abstract}

This paper describes some research work that was conducted by undergraduate mechanical engineering students at the University of Puerto Rico-Mayaguez during the past three years. The general research topics were heat transfer in open-cell aluminum foam and microprocessor control. The students' attitude, professionalism, independence, work habits, and intelligence ranged from average to outstanding. The upper-echelon students produced high enough quality work for presentation in engineering conferences and, with some extra input from the faculty, in engineering journals. The students were listed as co-authors in all publications. Three of the best students gave presentations of the results in four engineering forums. A few of the undergraduate students were even motivated to attend graduate school.

The undergraduate research experience was determined to be both successful and beneficial to both the students and the faculty. For the students, the benefits were numerous. They learned how to use research equipment, developed written and oral communication skills, gained experience in obtaining information and price estimates from manufacturers, and learned how to work within the university system to order materials and support conference travel. Furthermore, the students were able to acquire an insight into heat transfer and mechatronics, and they developed a great deal of pride in the findings and the presentations. For the faculty, the students helped develop course materials, helped establish and sustain a research program that provided a general research direction and enough preliminary results to write proposals for funding, and attract new graduate students. In addition, the university expectation to publish in conferences and journals was partially satisfied. The faculty also learned a great deal about working closely with and managing students. Such opportunities are not usually available in regular undergraduate engineering courses. This paper describes the research work, the students' feedback, and gives a general assessment of the research experience.

\section{Introduction}

Undergraduate research has gained significant popularity in many, if not most, of engineering schools in the past few years. Engineering undergraduate students are usually provided with some design experiences in the cap stone design courses and design-type projects 
in some other engineering courses throughout their curriculum. While valuable experiences, these design experiences are typically just applications of material that has already been covered in standard engineering curricula. In order to provide for the complete training of our future engineers, we must add a true research experience to the technical skills provided by our engineering curricula ${ }^{1}$. Our students should have the skills necessary to examine the current body of knowledge and participate in the extension of that knowledge to new research activities.

Engineering research includes the aspect of pursuing a scientific topic, a hypothesis or an idea in a systematic rigorous fashion in order to answer questions or to produce new and original knowledge. This aspect is not usually encountered in the typical undergraduate design projects. So an engineering student may graduate without taking part in a genuine research experience. This becomes a weakness, especially if the student pursues graduate studies or if the student works in an industrial environment that requires some engineering research. Undergraduate research programs are very likely to overcome such shortcomings and would provide the students with an approach to seek answers and a way of independent scientific thinking.

Teaching independent study courses of six to eight students does not require much course preparation, and the students can be evaluated on the outcomes of their research projects without spending a lot of time with written homework or exams. Furthermore, the students can assist in developing projects and handouts that can later be used as hands-on laboratory exercises or classroom demonstrations. At the same time, the students can acquire the background necessary for them to be valuable to a graduate research program, and the faculty member can perform the preliminary research necessary to secure funding for a graduate research program.

The current paper sheds some light on undergraduate research activities that were conducted at the Mechanical Engineering Department at the University of Puerto RicoMayaguez. Some preliminary activities concentrated on developing student skills necessary to conduct true research and involved small weekly activities using microprocessor control. Then, true undergraduate research projects were done in analytical modeling and experimental verification of the convective heat transfer of air flow in open-cell aluminum foam. This paper provides a general assessment of both activities and discusses the outcomes and the lessons learned.

\section{Research and Project Work}

\subsection{Participating Students}

A total of six mechanical engineering undergraduate students participated in the microprocessor activities and seven conducted the convective heat transfer research. The students were selected based on their character, professionalism, organizational and communication skills, knowledge of subject matter, motivation, and interest. Each student was interviewed by the advisor for no more than thirty minutes to assess the above attributes and to familiarize the student with the research topic. The students included both males and females in their senior year. The students worked individually or in groups of two on the research projects.

The students were either self-motivated, were paid a stipend, or they obtained course credits for participating in the research program. Some students combined two or all three advantages. The funding was available through an undergraduate research initiative provided by 
NASA that provided two hundred dollars per student for buying materials and eight hundred dollars as a student salary per semester.

Managing the students was challenging at times. It became difficult to keep track of the different tasks and interplay between them. It was also sometimes difficult to give the attention required for each student, so it was very important that good, highly-motivated and independent students were chosen for the project.

\subsection{Microprocessor Course}

This course was taught as an independent study class to six students, and focused on preparing students to conduct independent research. Students worked in groups of two and were given weekly tasks to complete using microprocessor control. At the end of each week, the students were required to give an oral presentation providing details about how they had solved the given task. Because this course was taught in the Mechanical Engineering Department, the students had very little experience in building electric circuits and no experience using microprocessors. To make up for this lack of experience, students were given detailed resources and general instructions for the first few weekly projects. As the semester progressed, students were given a task with specifications, but they needed to find their own resources and learn independently to complete the projects. Of course the instructor provided assistance when necessary, but the students were responsible for getting the information and resources they needed to complete the projects.

Because of the students' lack of experience, the first projects of the course were relatively simple and included an introduction to programming the microprocessor ${ }^{2}$ and building basic circuits. The coursework then progressed to include projects with light emitting diodes and switches, resistive and capacitative circuits, voltage dividers, infrared sensors, seven-segment displays, timing functions, analog to digital conversion, digital logic problems, transistor amplifiers, light sensors, frequency and sound applications, H-bridges, and motor control.

The purpose of this course was three fold. The first goal was to prepare students for independent research by developing their ability to independently gather background information and develop solutions for given tasks. The second goal was to develop laboratory skills in constructing circuits and using microprocessors that undergraduate mechanical engineering students were lacking. Finally, the project work that was done in this independent study course was later developed into an elective course for all mechanical engineering undergraduates.

\subsection{Heat Transfer Research}

This research project consisted of analytical modeling and experimental verification of the convective heat transfer of air flow in open-cell aluminum foam. This involved the treatment of the foam as a one lumped-parameter medium, in which the air and the aluminum were treated as one medium with average thermophysical properties. The analysis was one-dimensional and followed that of a thin fin $^{3}$.

The analytical part was a little more difficult than that of a typical undergraduate course in heat transfer. It required the use of control-volume analysis and the application of the 
conservation of energy principle to a relatively new situation. It also required the solution of a second-order ordinary differential equation, but no higher-level mathematics ${ }^{4}$.

The experimental part of the project involved verification runs to validate the analytical model. The one-dimensional temperature profile was measured using thermocouples located strategically at different points inside a foam block. The block was heated from one side and was placed in an open-loop wind tunnel. Room air was drawn through the foam using an axial fan. The temperature measurements were collected and recorded using an automatic data acquisition system. The flow rate of the air was determined from measurements of the dynamic pressure using a Pitot tube ${ }^{5,6,7}$. The experimental results were compared to the analytical model's results to validate it ${ }^{8}$.

To insure that the students completed the tasks assigned to them, meetings were held between the advisor and the students. The meeting time, frequency and formality depended on the professionalism, the motivation and the independence of each student. On average, there was no more than one meeting per week and each meeting lasted less than thirty minutes.

\section{Educational Assessment}

\subsection{Student Feedback for Microprocessor Course}

Because of the small class size, it was possible to interview all of the students to determine their opinions at the conclusion of the course. The students first interviewed each other and formed opinions about the successes and failures of this course. Then, each of the students had a one-on-one interview with the professor where they shared their opinions along with those of their classmates.

Every one of the six students was very satisfied with the material covered in the course. They also expressed appreciation for being able to take a course that was hands-on and that had direct applications in both graduate studies and in industrial positions. They liked being able to work independently on the weekly projects with a well-defined goal in mind. Two of the students also expressed pride in the fact that they were instrumental in developing a course that would be taught to future students.

As a testament to the effectiveness of this course, four of the six students involved have gone on to pursue graduate degrees. Two of the four have decided to specialize in areas related to microprocessor control of mechanical systems.

\subsection{Student Survey for Heat Transfer Research}

After the completion of the heat transfer research project, a survey of twenty-one questions was given to the students to complete. The survey was designed to get information and feedback on the following themes:

- students' enjoyment of the research,

- students' evaluation of what the program provided that is not available in the current curriculum, including the cap stone course,

- students' expectations about whether the research experience would be used after graduation, 
- effect of the research on the students' understanding and enjoyment of heat transfer

- amount of work, difficulty and time spent, and

- general expectations, improvements and opinions that the students presented.

The responses of the seven students were collected and analyzed to obtain general trends and assess the program. The following general statements can be made from interpretation of the surveys.

All students agreed that the research experience was very valuable and they enjoyed it. After completing the research, all students also agreed that they have enough confidence to conduct independent research. All students also agreed that they would continue the research, if they could and that they would highly recommend it to their friends. Five students said that the research was what they had expected it to be.

All students stated that the research provided them with things that the other courses in the curriculum did not offer. Five students said that the research provided them with experience not provided by the cap stone design course. The other two students have no opinion because they had not taken the course. All students also said they would use their experience after graduation.

All students also agreed that the research experience improved their attitude towards heat transfer and that they have more appreciation and understanding for it after completing the research.

Considering the course work load, five students thought the amount of work associated with the research was fair, but that the research did require time and effort. In estimating the weekly time required, the students gave a range of three to twelve hours. This depended on the personality and the work habits of the students. Six students thought the level of the difficulty was appropriate for an undergraduate curriculum.

Two students expressed a strong interest in wanting to be involved in multiple tasks and different aspects of the research program, i.e., combining the analytical and the experimental. Another two students suggested that all students involved should have been in contact and in group meetings and discussions. Students also commented on their enjoyment of learning how to use the experimental equipment and the hands-on experience. Two students enjoyed presenting the results in technical conferences ${ }^{4,5,6}$, while two other students complained about the facilities and the old equipment.

\section{Conclusion}

Overall, the instructors were very satisfied with the outcome of these activities. The time spent was minimal considering the benefits. The research was beneficial to the students in terms of increasing their confidence level towards scientific research, improving their attitude towards the topics and their written and oral communication skills. They also gained experience in obtaining information from manufacturers and ordering research equipment, and were able to attend conferences to present their material. In fact, most of the students involved in the 
activities mentioned have gone on to graduate study. For the faculty, the program helped develop course material, gather information for proposals, and developed conference publications. The faculty also learned a great deal about working closely with and managing students. Such opportunities are not usually available in regular undergraduate engineering courses. The authors recommend that the undergraduate research programs should be encouraged, especially for students interested in pursuing graduate studies.

\section{Bibliography}

1. M. P. Hodge and B. D. Lichter, "The union of therory and practice," Journal of Engineering Education, pp. 816821, May 1980.

2. Netmedia Inc., Support Documents for BX-24 Basic Express Microprocessor version 1.46, Tucson, AZ, 2000.

3. F. P. Incropera and D. P. De Witt, Fundamentals of Heat and Mass Transfer. Fifth Edition, John Willey and Sons, New York, pp. 130-133, , 2002.

4. N. Dukhan and P. D. Quiñones, "An equivalent thermal conductivity for open-cell metal foam for solar air heaters," Proceedings, the ISEC International Solar Energy Conference, Hawaii, USA, March 16-18, 2003.

5. C. Briano, J. Fontánez and N. Dukhan, "Characterization of the heat transfer in open-cell metal foam," Proceedings, Second International Conference on High Performance Structures and Materials, HPSM 2004, Ancona, Italy, May 31 to June $2^{\text {nd }}, 2004$.

6. C. Briano, J. Fontánez and N. Dukhan, "One-dimensional heat-transfer model for open-cell metal foam," The $14^{\text {th }}$ Undergraduate Research Symposium, Metropolitan University, San Juan, Puerto Rico, October $24-26$, 2003.

7. C. Briano, J. Fontánez and N. Dukhan, "Effect of flow rate on the heat transfer in 10-PPI aluminum foam," Presented at The $24^{\text {th }}$ Puerto Rico Interdisciplinary Scientific Meeting, Humacao, Puerto Rico, March 13, 2004.

8. N. Dukhan, P. D. Quiñones, C. Briano and J. Fontánez, "One-dimensional model for the combined heat transfer in open-cell metal foam," Proceedings, the ASME-ZSIS International Thermal Science Seminar, Bled, Slovenia, June $13-16,2004$.

\section{SCOTT KIEFER}

Scott Kiefer was an Assistant Professor of Mechanical Engineering at the University of Puerto Rico at Mayaguez until 2002 when he moved to Tri-State University. He received his B.S. degree in Mechanical Engineering from the University of Wisconsin at Platteville, and his M.S. and Ph.D. in Mechanical Engineering from North Carolina State University.

\section{NIHAD DUKHAN}

Nihad Dukhan is an Associate Professor of Mechanical Engineering at the University of Puerto Rico at Mayaguez. He received his B.S., M.S., and Ph.D. in Mechanical Engineering from the University of Toledo. 